\title{
Maternal pregestational glucose level and adverse neonatal outcomes: a population-based retrospective cohort study
}

\section{Mengyao Zeng}

Shanghai Institute of Planned Parenthood Research

\section{Yang He}

Chongqing Population And Family Planning Science And Technology Research Institute

Min Li

Shanghai Institute Of Planned Parenthood Research

\section{Liu Yang}

Chongqing Population And Family Planning Science And Technology Research Institute

\section{Qianxi Zhu}

Shanghai Institute of Planned Parenthood Research

\section{Jun Liu}

Chongqing Population And Family Planning Science And Technology Research Institute

\section{Yanyan Mao}

Shanghai Institute Of Planned Parenthood Research

\section{Qing Chen}

Chongqing Population And Family Planning Science And Technology Research Institute

\section{Jing Du}

Shanghai Institute of Planned Parenthood Research

\section{Weijin Zhou ( $\sim$ zw0822@sina.com )}

Shanghai Institute Of Planned Parenthood Research https://orcid.org/0000-0002-0958-2866

\section{Research article}

Keywords: Fasting blood glucose, Hyperglycemia, Hypoglycemia, Macrosomia, Neonatal outcomes, Preconception care

Posted Date: September 1st, 2020

DOI: https://doi.org/10.21203/rs.3.rs-61699/v1

License: (1) (i) This work is licensed under a Creative Commons Attribution 4.0 International License. Read Full License 


\section{Abstract}

Background: Women with diabetes or hyperglycemia during the pregnancy have been proved to be at increased risk for adverse outcomes such as primary cesarean section rate and macrosomia. However, a lack of studies have focused on the maternal glucose level prior to the pregnancy and the effect of maternal pregestational hyperglycemia or hypoglycemia on pregnancy outcomes is unclear. Hence, we conducted this study to investigate the association between maternal pregestational fasting blood glucose level and adverse neonatal outcomes.

Methods: A retrospective cohort study was conducted in the Chongqing Municipality of China between April 2010 and December 2016. A total of 54365 women with their live birth singletons from all 39 counties of Chongqing who participated in the National Free Preconception Health Examination Project were included. They all took a once fasting glucose testing within one year prior to pregnancy and without a definite diagnosis of diabetes at that point. Our primary outcomes were preterm birth, very preterm birth, macrosomia, large for gestational age (LGA), low birth weight (LBW) and small for gestational age (SGA).

Results: Of the 54365 women, 2813 (5.17\%) were hypoglycemia, 48400 (89.03\%) were normoglycemia, 2582 (4.75\%) had impaired fasting glucose (IFG) and 570 (1.05\%) were diabetic hyperglycemia. Compared to the normoglycemia group, women with pregestational glucose at the diabetic level had a higher rate of macrosomia (4.16\% vs. $6.18 \%)$, while impaired fasting glucose group seemed to be associated with decreased risks for preterm birth (7.38\% vs. $5.78 \%)$, very preterm birth ( $1.25 \%$ vs. $0.74 \%)$, LBW (1.18\% vs. $0.59 \%)$ and SGA (5.92\% vs. $4.29 \%)$, p<.05 for all. No significant difference was found between hypoglycemia and normoglycemia in the neonatal outcomes. After adjusting for potential confounders, pregestational diabetic hyperglycemia was remained significantly associated with an increased risk for macrosomia (aRR, 1.49; 95\% Cl, 1.07-2.09).

Conclusion: Though without an overt diabetes mellitus, women with once diabetic fasting glucose level during their preconception examinations were still associated with an increased risk for macrosomia. Once fasting glucose within one year before pregnancy might also be considered as an early sign to help the obstetricians to prejudge and control the risk of macrosomia in advance.

\section{Introduction}

Pregestational diabetes mellitus (PGDM), which referred to women with definite diabetes mellitus before pregnancy, has been proved to be positively associated with adverse pregnancy outcomes for both mothers and their fetuses, including pregnancy complications, macrosomia and congenital anomalies [1-3]. For women with PGDM, specific intervention on dietary and physical exercise before or during their pregnancies have shown to be effective in reducing some diabetes-related adverse outcomes $[4,5]$.

Although a series of large cohort studies, the Hyperglycemia and Adverse Pregnancy outcome (HAPO) studies have shown that increasing maternal glucose levels during pregnancy regardless of gestational diabetes mellitus (GDM) status are associated with increased risks for adverse perinatal outcomes such as LGA and macrosomia [6-8], and there is some evidence showing that a mild maternal hyperglycemia prior to pregnancy might also be associated with increased risks for GDM and LGA in some specific group such as women with polycystic ovary syndrome or received assisted reproductive technology $[9,10]$, lack of studies focus on the preconception maternal glucose level in general population and it remains uncertain whether maternal abnormal glucose level in the absence of overt diabetes before pregnancy are related to any adverse pregnancy outcomes. 
Given this uncertainty, whether and how to provide health care before the pregnancy to these women who had abnormal glucose levels but without overt diabetes mellitus is unclear. According to the current non-official guideline of diabetes screening and management for pregnant women in China (Supplemental Figure S1), women will be tested for diabetes at their preconception care visit or the first prenatal visit by using standard diagnostic criteria, and receive a testing for GDM at 24-28 weeks of gestation if not previously known to have diabetes by $75 \mathrm{~g}$ oral glucose tolerance test (OGTT) [11, 12]. Since the diagnostic criteria for diabetes are a little "restrictive" for asymptomatic people, which need to repeat the testing for abnormal results on another day, a significant percentage of people with abnormal glycose levels are undiagnosed diabetics $[13,14]$. It was also reported that there were many PGDM women missed diagnosis before pregnancy in China, with a great proportion $(67.8 \%, 506 / 746)$ in one study conducted in Beijing [15]. Hence, the impact of the abnormal maternal glucose before pregnancy on perinatal outcome regardless of GDM status is needed to be evaluated for a better risk assessment and consultation during the preconception period.

Our study was to examine the association between maternal pregestational glucose and adverse neonatal outcomes related to the gestational age and birth weight, which might provide a new sign or better criteria to manage the potential high-risk women in advance and improve their pregnancy outcomes.

\section{Research Design And Methods}

\section{Study design and Participants}

We conducted this population-based, retrospective cohort study in Chongqing Municipality of China. The participants were women recruited from the National Free Preconception Health Examination Project (NFPHEP), which was a national project launched to provide free pregestational health examinations, consultations and risk assessments during their early pregnancy and postpartum follow-ups for couples who were willing to pregnant recently, aiming to improve the maternal and infant health in China. The detailed information about the procedures and implementation of this project have been well described previously [16-18]. We extracted Chongqing data from the national NFPHEP database regarding the preconception care and pregnancy outcomes of 68266 women from April 2010 to December 2016. The eligibility criteria for inclusion were the women aged 20-49 years, accepted the preconception health examination and without a definite diagnosis of diabetes. Women who failed to take pregestational blood glucose testing or did not have singleton livebirth were excluded. It should be noted that since we found there were inaccurate blood glucose measurements in one of the Chongqing counties from 2012 to 2013 under our quality control, we decided to delete these 609 subjects of the county in our study. The flowchart of the study population was shown in Figure 1. Our final analyses included 54365 women with their singleton babies who had complete information of basic characteristics we were interested in, including age, BMl, ethnicity, education level, occupation, place of residence, living habits, history of childbearing and blood pressure.

The study had been approved by the Institutional Review Board of the Chinese Association of Maternal and Child Health Studies. Written informed consent was provided from all participants.

\section{Exposure Assessment}

When the participants enrolled in the project prior to the pregnancy, their baseline characteristics, including demographic data, living habits, history of chronic diseases and history of pregnancy were collected by the local trained health workers with a standardized questionnaire. Blood glucose concentrations of the participants were measured in the clinic lab by their overnight fasting blood samples collected during the preconception health examination. Fasting blood glucose (FBG) concentrations were analyzed by using the automatic analyzers chosen by 
the local laboratories, all of which were approved by the China Food and Drug Administration. Pregnancy outcomes of participants were recorded at the postpartum follow-up within 42 days after delivery.

We divided the participants into four subgroups by their venous blood glucose levels: hypoglycemia, normoglycemia, impaired fasting glucose (IFG) and diabetic hyperglycemia. According to the latest guidelines of American Diabetes Association, hypoglycemia was defined as having FBG $<3.9 \mathrm{mmol} / \mathrm{L}$ and hyperglycemia was defined as having FBG $\geq 6.1 \mathrm{mmol} / \mathrm{L}$ [19]. In hyperglycemia, IFG was defined as FBG levels between 6.1 and $6.9 \mathrm{mmol} / \mathrm{L}$, while the criteria for diabetes was a person with FBG equal or more than $7.0 \mathrm{mmol} / \mathrm{L}[20,21]$. It should be noted that although we used "diabetes" here, it was not a definite diagnosis because of no other information on clinical features, results of OGTT or multiple fasting glucose tests recorded in our data. Hypertension was defined as a systolic blood pressure $\geq 140$ $\mathrm{mmHg}$, and/or diastolic blood pressure $\geq 90 \mathrm{mmHg}$.[22] Maternal Body Mass Index (BMI) was categorized into four groups according to the Working Group of China (WGOC) definition (<18.5, 18.5-23.9, 24.0-27.9, or $\geq 28.0 \mathrm{~kg} / \mathrm{m}^{2}$ ) $[23,24]$. Time to conception there was defined as the period between the date of glucose testing and the date of last menstrual period of pregnant women.

\section{Outcome Definition}

As for the outcomes in this study, preterm birth (PTB) was defined as delivery at less than 37 completed gestational weeks. Very preterm birth (VPTB) was the delivery earlier than 32 completed gestational weeks. Low birth weight (LBW) was defined as birth weight less than 2,500 grams, while macrosomia was neonates with birth weight equal or above 4,000 grams. Small for gestational age (SGA) or LGA was defined as birth weight < 10 th or $>90$ th percentile, respectively, based on the Chinese neonatal birth weight curve for each gestational age established in 2015 [25].

\section{Statistical analysis}

The proportions of maternal baseline characteristics according to the four pregestational glucose levels were grouped and computed. Pearson Chi-square tests were used to examine the univariate associations of these categorical characteristics with glucose level. Mean (SD) for neonatal continuous characteristics among the four glucose groups were calculated and tested by one-way ANOVA analysis. Poisson regression models were used to estimate the effect of pregestational glucose on the risk of adverse birth outcomes. Each result was presented as a risk ratio (RR) with its 95\% confidence interval (CI) of hypoglycemia, IFG and diabetic hyperglycemia compared to the normoglycemia group. RR with its $95 \% \mathrm{Cl}$ were also calculated by adjusting for potential confounders including maternal age, BMI, ethnicity, education level, place of residence, occupation, smoking and passive smoking, alcohol, gravidity and history of PTB and abortion (both spontaneous and induced). Subgroup analysis was used to examine the aRRs and $95 \% \mathrm{Cls}$ of macrosomia for women with the pregestational diabetic hyperglycemia among different subgroups on the baseline characteristics. Statistical analyses were conducted using SAS statistical software (9.4 version). A 2-tailed level of .05 was considered the statistical significance.

\section{Results}

Of the 54365 mother-neonate pairs, 2813 (5.17\%) were hypoglycemia, 48400 (89.03\%) were normoglycemia, 2582 (4.75\%) were IFG, and 570 (1.05\%) women were diabetic hyperglycemia. No significant difference in maternal smoking $(p=0.808)$ or history of preterm birth $(p=0.916)$ was found among the four groups (Table 1$)$. Other characteristics including maternal age, maternal BMI, ethnicity, education level, occupation, place of residence, passive smoking, alcohol consumption, gravidity, parity, hypertension, history of spontaneous abortion and history of induced abortion were all statistically significantly differed from the four groups of the glucose levels. We found that hyperglycemia (IFG and diabetic) women had a higher proportion of advanced maternal age (age 35 or more) than the 
women in hypoglycemia and normal group (5.77\% and $8.07 \%$ vs. $2.49 \%$ and $3.37 \%$, respectively), had a higher percentage of overweight and obesity ( $12.90 \%$ and $16.67 \%$ vs. $9.32 \%$ and $11.36 \%$, respectively), and with a relatively lower education level as well as a higher proportion of agricultural residence registration. Women in the hypoglycemia group had the highest percentage of passive smoking and alcohol consumption in this study. Women with IFG and diabetic hyperglycemia were more likely to have hypertension than in hypoglycemia and normal groups (2.90\% and $2.28 \%$ vs. $1.24 \%$ and $1.41 \%$, respectively). Women with pregestational diabetic hyperglycemia also had the highest proportion of multigravida (53.16\%) and multipara (32.81\%). As for the birth outcomes, hyperglycemia women (IFG and diabetic) seemed to have a newborn with higher birthweight than the other groups though the difference was not significant $(p=0.151)$. No clear difference was found among the four groups in neonate gender $(p=0.858)$ and gestational age in days $(p=0.103)$.

\section{Table 1 Maternal and neonatal characteristics according to pregestational glucose}




\begin{tabular}{|c|c|c|c|c|c|}
\hline \multirow[t]{2}{*}{ teristics } & \multirow[b]{2}{*}{$\begin{array}{l}\text { Hypoglycemia } \quad(<3.9 \\
\mathrm{mmol} / \mathrm{L})\end{array}$} & \multirow[b]{2}{*}{$\begin{array}{l}\text { Normoglycemia } \\
6.0 \mathrm{mmol} / \mathrm{L})\end{array}$} & \multicolumn{2}{|c|}{ Hyperglycemia $(\geq 6.1 \mathrm{mmol} / \mathrm{L})$} & \multirow{2}{*}{$\begin{array}{c}\mathrm{p}- \\
\text { value }\end{array}$} \\
\hline & & & $\begin{array}{c}\text { IFG } \\
(6.1-6.9 \mathrm{mmol} / \mathrm{L}\end{array}$ & $\begin{array}{c}\text { Diabetic } \\
(\geq 7.0 \mathrm{mmol} / \mathrm{L} \square\end{array}$ & \\
\hline ticipants (\%) & 2813 (5.17) & $48400(89.03)$ & $2582(4.75)$ & $570(1.05)$ & \\
\hline 3 & & & & & $<0.001$ \\
\hline $20-24$ & $1534(54.53)$ & $22735(46.97)$ & $1318(51.05)$ & $278(48.77)$ & \\
\hline $25-29$ & $994(35.34)$ & $19430(40.14)$ & $866(33.54)$ & $187(32.81)$ & \\
\hline $30-34$ & $215(7.64)$ & $4606(9.52)$ & $249(9.64)$ & $59(10.35)$ & \\
\hline $35-49$ & $70(2.49)$ & 1629 (3.37) & $149(5.77)$ & $46(8.07)$ & \\
\hline $\mathrm{.}^{2}$ & & & & & $<0.001$ \\
\hline$<18.5$ & $507(18.02)$ & $7409(15.31)$ & $367(14.21)$ & $65(11.40)$ & \\
\hline $18.5-23.9$ & $2044(72.66)$ & $35494(73.33)$ & $1882(72.89)$ & $410(71.93)$ & \\
\hline $24-27.9$ & $223(7.93)$ & $4736(9.79)$ & $268(10.38)$ & $77(13.51)$ & \\
\hline$\geq 28$ & 39 (1.39) & $761(1.57)$ & $65(2.52)$ & $18(3.16)$ & \\
\hline & & & & & $<0.001$ \\
\hline Han & $2608(92.71)$ & $46251(95.56)$ & $2517(97.48)$ & $557(97.72)$ & \\
\hline Others & $205(7.29)$ & $2149(4.44)$ & $65(2.52)$ & $13(2.28)$ & \\
\hline $\mathrm{L}$ & & & & & $<0.001$ \\
\hline ary or below & $97(3.45)$ & $1926(3.98)$ & $180(6.97)$ & $48(8.42)$ & \\
\hline Middle school & $1276(45.36)$ & $21011(43.41)$ & $1252(48.49)$ & $288(50.53)$ & \\
\hline High school & $784(27.87)$ & 12237 (25.28) & $603(23.35)$ & 135 (23.68) & \\
\hline lege or above & $656(23.32)$ & $13226(27.33)$ & 547 (21.19) & 99 (17.37) & \\
\hline ssidence & & & & & $<0.001$ \\
\hline ı-agricultural & $651(23.14)$ & $12903(26.66)$ & $542(20.99)$ & $109(19.12)$ & \\
\hline Agricultural & $2162(76.86)$ & 35497 (73.34) & $2040(79.01)$ & $461(80.88)$ & \\
\hline in & & & & & $<0.001$ \\
\hline Peasant & $1290(45.86)$ & 21257 (43.92) & $1340(51.90)$ & 318 (55.79) & \\
\hline labor worker & $288(10.24)$ & $4901(10.13)$ & $273(10.57)$ & $61(10.70)$ & \\
\hline Merchant & $456(16.21)$ & $5271(10.89)$ & 237 (9.18) & $70(12.28)$ & \\
\hline service staff & $101(3.59)$ & 1745 (3.61) & $93(3.60)$ & $15(2.63)$ & \\
\hline Housewife & $145(5.15)$ & $2911(6.01)$ & 77 (2.98) & $23(4.04)$ & \\
\hline Civil servant & $324(11.52)$ & 7688 (15.88) & 276 (10.69) & $44(7.72)$ & \\
\hline Others & $209(7.43)$ & $4627(9.56)$ & $286(11.08)$ & $39(6.84)$ & \\
\hline & & & & & 0.808 \\
\hline No & 2799 (99.50) & 48093 (99.37) & $2567(99.42)$ & 567 (99.47) & \\
\hline Yes & $14(0.50)$ & $307(0.63)$ & $15(0.58)$ & $3(0.53)$ & \\
\hline noking & & & & & $<0.001$ \\
\hline No & $2229(79.24)$ & 40562 (83.81) & $2252(87.22)$ & 494 (86.67) & \\
\hline Yes & $584(20.76)$ & 7838 (16.19) & 330 (12.78) & 76 (13.33) & \\
\hline & & & & & $<0.001$ \\
\hline No & $2579(91.68)$ & $45583(94.18)$ & $2486(96.28)$ & $544(95.44)$ & \\
\hline Yes & 234 (8.32) & 2817 (5.82) & $96(3.72)$ & $26(4.56)$ & \\
\hline & & & & & $<0.001$ \\
\hline 0 & $1620(57.59)$ & 23415 (48.38) & $1293(50.08)$ & $267(46.84)$ & \\
\hline$\geq 1$ & $1193(42.41)$ & 24985 (51.62) & $1289(49.92)$ & $303(53.16)$ & \\
\hline & & & & & 0.001 \\
\hline 0 & $2088(74.23)$ & 34767 (71.83) & $1900(73.59)$ & 383 (67.19) & \\
\hline$\geq 1$ & 725 (25.77) & $13633(28.17)$ & $682(26.41)$ & $187(32.81)$ & \\
\hline preterm & & & & & 0.916 \\
\hline No & 2807 (99.79) & 48296 (99.79) & 2576 (99.77) & 568 (99.65) & \\
\hline Yes & $6(0.21)$ & $104(0.21)$ & $6(0.23)$ & $2(0.35)$ & \\
\hline jus abortion & & & & & 0.003 \\
\hline No & $2714(96.48)$ & $46105(95.26)$ & $2468(95.58)$ & 554 (97.19) & \\
\hline
\end{tabular}




\begin{tabular}{|c|c|c|c|c|c|}
\hline \multirow{2}{*}{ induced } & $99(3.52)$ & $2295(4.74)$ & $114(4.42)$ & $16(2.81)$ & \multirow{2}{*}{$<0.001$} \\
\hline & & & & & \\
\hline No & 2044 (72.66) & 30991 (64.03) & $1701(65.88)$ & $385(67.54)$ & \\
\hline Yes & $769(27.34)$ & 17409 (35.97) & $881(34.12)$ & $185(32.46)$ & \\
\hline sion & & & & & $<0.001$ \\
\hline No & 2778 (98.76) & 47716 (98.59) & 2507 (97.1) & 557 (97.72) & \\
\hline Yes & $35(1.24)$ & $684(1.41)$ & 75 (2.90) & $13(2.28)$ & \\
\hline jender & $1475(52.62)$ & $25018(51.91)$ & $1320(51.56)$ & $291(51.32)$ & 0.858 \\
\hline al age, days & $275.33 \pm 14.59$ & $275.11 \pm 14.26$ & $276.05 \pm 13.00$ & $275.16 \pm 12.02$ & 0.103 \\
\hline jirth weight, & $3304.30 \pm 406.06$ & $3298.44 \pm 393.48$ & $3319.21 \pm 364.29$ & $3311.19 \pm 409.30$ & 0.151 \\
\hline
\end{tabular}

The rate of PTB among hypoglycemia, normoglycemia, IFG and diabetic hyperglycemia was 7.73\%, 7.38\%, 5.78\% and $7.72 \%$, respectively, which seemed there was a decreased risk for PTB in women with IFG (Table 2). Similarly, the IFG group also had lower rates of VPTB. It was worth noting that diabetic hyperglycemia group had a clear higher rate of macrosomia the other groups (6.18\% vs. $4.60 \%$ and $4.16 \%$ and $4.32 \%)$. Compared with the normoglycemia group, diabetic hyperglycemia had statistically significant higher risks for macrosomia (aRR, 1.49; 95\% Cl, 1.07-2.09) after adjusting the potential confounders. No significant differences were found in all birth outcomes here between hypoglycemia and normoglycemia. As for the outcome LBW or SGA, even for the PTB and VPTB, it showed there was a protective effect of IFG compared to the reference, although no significant differences were observed in diabetic hyperglycemia group.

Table 2 Associations between pregestational glucose and adverse birth outcomes 


\begin{tabular}{|c|c|c|c|c|}
\hline & \multirow[b]{2}{*}{$\underset{\mathrm{mmol} / \mathrm{L})}{\operatorname{Hypoglycemia}}(<3.9$} & \multirow[b]{2}{*}{$\begin{array}{c}\text { Normoglycemia (3.9-6.0 } \\
\mathrm{mmol} / \mathrm{L})\end{array}$} & \multicolumn{2}{|c|}{ Hyperglycemia ( $\geq 6.1 \mathrm{mmol} / \mathrm{L})$} \\
\hline & & & $\begin{array}{c}\text { IFG } \\
(6.1- \\
6.9 \mathrm{mmol} / \mathrm{L} \square\end{array}$ & $\begin{array}{c}\text { Diabetic } \\
(\geq 7.0 \mathrm{mmol} / \mathrm{L} \square\end{array}$ \\
\hline \multicolumn{5}{|l|}{ Births } \\
\hline$\%)$ & $217(7.73)$ & 3565 (7.38) & $149(5.78)$ & $44(7.72)$ \\
\hline ljusted RR & $1.05(0.91-1.20)$ & 1.00 & $0.78(0.67-0.92)$ & $\begin{array}{l}1.05(0.78- \\
1.41)\end{array}$ \\
\hline sted $\mathrm{RR}^{1}$ & $1.03(0.90-1.18)$ & 1.00 & $0.78(0.67-0.92)$ & $\begin{array}{c}1.04(0.77- \\
1.40)\end{array}$ \\
\hline \multicolumn{5}{|l|}{ term Births } \\
\hline$\%)$ & 33 (1.18) & $602(1.25)$ & $19(0.74)$ & $6(1.05)$ \\
\hline $\begin{array}{l}\text { ljusted } \\
\text { CI) }\end{array}$ & $0.94(0.67-1.34)$ & 1.00 & $0.59(0.38-0.93)$ & $\begin{array}{c}0.84(0.38- \\
1.89)\end{array}$ \\
\hline $\begin{array}{l}\text { sted } \\
\text { oCI) }\end{array}$ & $0.94(0.67-1.34)$ & 1.00 & $0.59(0.37-0.93)$ & $\begin{array}{l}0.78(0.35- \\
1.75)\end{array}$ \\
\hline mia & & & & \\
\hline$\%)$ & $126(4.60)$ & $1992(4.16)$ & $110(4.32)$ & $35(6.18)$ \\
\hline $\begin{array}{l}\text { ljusted } \\
\text { CI) }\end{array}$ & $1.11(0.93-1.32)$ & 1.00 & $1.04(0.86-1.26)$ & $\begin{array}{c}1.49(1.06- \\
2.08)\end{array}$ \\
\hline $\begin{array}{l}\text { sted } \\
\text { oCI) }\end{array}$ & $1.17(0.98-1.40)$ & 1.00 & $1.07(0.88-1.29)$ & $\begin{array}{l}1.49(1.07- \\
2.09)\end{array}$ \\
\hline$\%)$ & $285(10.25)$ & $4692(4.81)$ & $237(9.33)$ & $61(10.80)$ \\
\hline $\begin{array}{l}\text { ljusted } \\
\text { CI) }\end{array}$ & $1.04(0.93-1.18)$ & 1.00 & $0.95(0.83-1.08)$ & $\begin{array}{c}1.10(0.86- \\
1.42)\end{array}$ \\
\hline $\begin{array}{l}\text { sted } \\
\text { oCI) }\end{array}$ & $1.07(0.95-1.20)$ & 1.00 & $0.96(0.85-1.10)$ & $\begin{array}{l}1.08(0.84- \\
1.40)\end{array}$ \\
\hline$\%)$ & $40(1.44)$ & $564(1.18)$ & $15(0.59)$ & $7(1.24)$ \\
\hline $\begin{array}{l}\text { ljusted } \\
\text { CI) }\end{array}$ & $1.22(0.89-1.68)$ & 1.00 & $0.50(0.30-0.84)$ & $\begin{array}{c}1.05(0.50- \\
2.21)\end{array}$ \\
\hline $\begin{array}{l}\text { sted } \\
\text { oCI) }\end{array}$ & $1.21(0.88-1.67)$ & 1.00 & $0.52(0.31-0.87)$ & $\begin{array}{l}1.10(0.52- \\
2.33)\end{array}$ \\
\hline$\%)$ & $170(6.12)$ & $2832(5.92)$ & $109(4.29)$ & $28(4.96)$ \\
\hline $\begin{array}{l}\text { ljusted } \\
\text { CI) }\end{array}$ & $1.03(0.89-1.21)$ & 1.00 & $0.72(0.60-0.88)$ & $\begin{array}{l}0.84(0.58- \\
1.21)\end{array}$ \\
\hline $\begin{array}{l}\text { sted } \\
\text { oCI) }\end{array}$ & $1.02(0.87-1.19)$ & 1.00 & $0.72(0.60-0.88)$ & $\begin{array}{c}0.86(0.59- \\
1.25)\end{array}$ \\
\hline
\end{tabular}

The cumulative occurrence of macrosomia by glucose level was presented in Figure 2, which revealed that women with diabetic glucose level before pregnancy could be associated with an increased risk of macrosomia clearly. From 39 to 42 gestational weeks, the cumulative proportion of macrosomia happened in diabetic hyperglycemia group was about 1.5 times as it in the other three groups.

Subgroup analysis of macrosomia in diabetic hyperglycemia compared to the normoglycemia group was shown in Figure 3. Although there was an overall higher risk of macrosomia in pregestational diabetic hyperglycemia, the impact of high blood glucose level appeared to be somewhat "masked" by some characteristics such as higher age, passive smoking and history of abortion. In addition, we found that compared to the normoglycemia group, pregestational diabetic hyperglycemia was associated with significantly higher rates of macrosomia if the women bearing a male fetus (aRR, $1.85 ; 95 \% \mathrm{Cl}, 1.26-2.71)$, but there was no difference in risk of macrosomia between different glucose groups among women bearing a female fetus (aRR, 0.94; 95\% Cl, 0.47-1.89). The analysis also indicated that the closer the glucose test was to pregnancy, the more clinically significant its result was. As it was shown, among the women who took the pregestational health examinations within three months before their 
pregnancies, diabetic hyperglycemia was a better predictor sign of a higher risk of macrosomia $(\mathrm{aRR}, 1.64 ; 95 \% \mathrm{Cl}$, 1.13-2.39).

\section{Discussion}

In our study which aimed to evaluate the association between pregestational maternal glucose level and singleton neonatal outcome, we found that pregestational maternal diabetic hyperglycemia was associated with an increased risk for macrosomia and pregestational IFG seemed to be associated with lower rates of LBW and SGA, and even with PTB and VPTB.

To our knowledge, the association between GDM or PGDM and pregnancy outcomes have been well studied, regardless of in the population [26, 27], or at the molecular level [28-30]. And in recent years, researchers began to focus on the association of IFG during the pregnancy with adverse perinatal outcomes and later diabetes mellitus. While the HAPO study has established the relationship of glycose levels below the diagnostic of diabetes during the pregnancy with GDM and increased birth weight [6,31,32], few projects studied on the pre-pregnancy maternal glucose among women without overt diabetes mellitus, and its association with later pregnancy or delivery was still uncertain. In our study, we found a significant association between diabetic glucose level within one year before pregnancy and macrosomia, indicating that diabetic hyperglycemia in once fasting glucose test during the preconception examination might also be an early sign of macrosomia.

This finding was compatible with similar but different studies. In previous studies as we know, women with GDM, PGDM, first-trimester hyperglycemia, or mild hyperglycemia at the late trimester, were all proved to be associated with increased risk of macrosomia or LGA [6, 31, 33-35]. And then, our finding indicated that the existing insulin resistance prior to pregnancy might also have an influence on the mothers and their fetuses during the pregnancy or at the delivery, although its degree was under the current diagnostic of diabetes. As a result, the current standard diagnostic criteria of diabetes might be a little strict for women who prepared for pregnancy. Earlier prejudge and proper intervention needs to be taken into consideration for hyperglycemia women in the absence of overt diabetes during the period of preparing for pregnancy.

In addition, there was an interesting finding that the possible effect of maternal diabetic hyperglycemia before pregnancy on macrosomia appeared to be somewhat greater in male fetus than the female fetus. This difference also existed in LGA, which suggested that it cannot just be interpreted by gender or gestational age. A previous study in Spain has shown a similar result that GDM was only a predictor of macrosomia in male fetuses [36]. According to their interpretation, the difference by fetal sex might due to the higher frailty of male fetuses to external influences during the pregnancy, which means male fetuses would be more affected by maternal hyperglycemia and then to be overweight.

Questions have been raised for the possible benefits of pregestational IFG in neonatal outcomes among pregnant women. In our study, the "mild hyperglycemia" prior to the pregnancy might be a protective factor to some adverse birth outcomes including LBW, SGA, PTB and VPTB. Moreover. it did not increase the risks of macrosomia and LGA as diabetic hyperglycemia did. However, this finding was inconsistent with one similar study in Guangdong province of China, which suggested that maternal pre-pregnancy IFG increased the risk of PTB (aRR, 1.07; 95\% Cl, 1.02-1.12) and LGA (aRR, 1.10; 95\% Cl, 1.06-1.14) [37]. Another study focusing on the pre-pregnancy IFG found that there was no significant difference in neonatal outcome in women with IFG from the normoglycemia group, but it might be associated with increased risks for maternal outcomes including gestational diabetes and mild preeclampsia [38] Based on their finding that pregestational maternal IFG was associated with GDM and the guideline of diabetes 
management for pregnant women in China, we guessed that the protective effect of IFG in our study might be influenced by the intervention such as healthy diet, exercise or insulin taking during the pregnancy to some certain, for there was some evidence showing that treating women with "mild" gestational diabetes mellitus could improve birth outcome [39], but it should be interpreted with caution due to the insufficient data. It also inspired us that the analysis of associations between pregestational hyperglycemia and maternal outcomes, such as GDM, pregnancy hypertension and mild preeclampsia, which information was lacking in NFPHEP database, should be considered in our further study.

As we know, this is one of the few studies with large sample size addressing the impact of glucose level prior to pregnancy on neonatal outcomes among the general women at childbearing age. The strength of our study is the large cohort based on an unselected population covering almost the whole Chongqing Municipality of China, which supports good generalizability of our finding. Our study also has some limitations. Since it is a retrospective cohort study design, our database lacks some important information during the pregnancy period which cannot be collected again. We do not know if the diabetic hyperglycemia women also had a high glucose level during their pregnancies, or whether they had any treatment or intervention to fight with the insulin resistance after their preconception health examinations. Therefore, the findings of our study should be interpreted with caution, since the lack of information might have an impact on the final associations of pregestational glucose level with birth outcomes. Although the lack of information brought uncertainty and possible bias, we inclined to think that the significant risk of macrosomia in pregestational diabetic hyperglycemia women might be underestimated, due to their higher probabilities of developing GDM $[10,38]$, and the possible subsequent intervention. The aRR of macrosomia might be higher if there was not any intervention before and during pregnancy.

In this retrospective cohort from preconception to delivery, we suggested that pregestational diabetic hyperglycemia is associated with a higher risk of macrosomia. Diabetic hyperglycemia in just one fasting blood glucose testing within one year before the pregnancy might be considered as an early sign of overweight neonates. As no uniform guidelines for pre-pregnancy care on blood glucose management in China and many other developing countries currently, such evidence could count towards justification of official guidelines for maternal blood glucose testings and related interventions during pre-pregnancy care to improve pregnancy outcomes. Further high-quality prospective studies, which included the information of the mothers during the pregnancy, are needed to investigate the effect of pregestational glucose level on the maternal outcome and the metabolic-related variables during the pregnancy.

\section{Declarations}

\section{Acknowledgements}

None.

\section{Author Contributions}

M.Z. researched the literature; conceived and designed the study; analyzed and interpreted the data; and wrote the manuscript and figures. M.L. and W.Z. conceived and designed the study, researched the literature, and participated in data curation and manuscript writing. J.L., Y.H., L.Y. and Q.C. conducted the study, acquired data and participated in writing the manuscript. Q.Z., J.D. and Y.M. helped to interpret the data and revised the manuscript before submission. All authors critically reviewed and provided intellectual input on the manuscript and approved the final draft for publication.

\section{Ethics approval}

Page 10/16 
This study had been reviewed and approved by the Ethics Committee of NHC Key Laboratory of Birth Defects and Reproductive Health (Chongqing Population and Family Planning Science and Technology Research Institute) on 13 April 2017. Written informed consent was provided from all participants.

\section{Data Availability Statement}

All data relevant to the study are included in the article or uploaded as supplementary information.

Competing interests

The authors have declared that no competing interests exist.

\section{References}

1. vonKries R, Kimmerle R, Schmidt JE, Hachmeister A, Bohm O, Wolf HG: Pregnancy outcomes in mothers with pregestational diabetes: A population-based study in North Rhine (Germany) from 1988 to 1993. European Journal of Pediatrics 1997, 156(12):963-967.

2. Vambergue A, Fajardy I: Consequences of gestational and pregestational diabetes on placental function and birth weight. World journal of diabetes 2011, 2(11):196-203.

3. Sibai BM, Caritis SN, Hauth JC, MacPherson C, VanDorsten JP, Klebanoff M, Landon M, Paul RH, Meis PJ, Miodovnik $\mathrm{M}$ et al: Preterm delivery in women with pregestational diabetes mellitus or chronic hypertension relative to women with uncomplicated pregnancies. American Journal of Obstetrics and Gynecology 2000, 183(6):1520-1524.

4. Wahabi HA, Alzeidan RA, Bawazeer GA, Alansari LA, Esmaeil SA: Preconception care for diabetic women for improving maternal and fetal outcomes: a systematic review and meta-analysis. BMC pregnancy and childbirth 2010, 10:63.

5. Xie GH, Zheng Z, Liu TC, Qing LL, Hong XQ, Zha WT, Lv Y: Health care and risk of adverse pregnancy outcomes among diabetic women: an updated meta-analysis. Arch Gynecol Obstet 2019, 299(3):891-899.

6. Metzger BE, Lowe LP, Dyer AR, Trimble ER, Chaovarindr U, Coustan DR, Hadden DR, McCance DR, Hod M, Mclntyre HD et al: Hyperglycemia and adverse pregnancy outcomes. New England Journal of Medicine 2008, 358(19):1991-2002.

7. Lowe LP, Metzger BE, Dyer AR, Lowe J, McCance DR, Lappin TRJ, Trimble ER, Coustan DR, Hadden DR, Hod M et al: Hyperglycemia and Adverse Pregnancy Outcome (HAPO) Study Associations of maternal A1C and glucose with pregnancy outcomes. Diabetes Care 2012, 35(3):574-580.

8. Boriboonhirunsarn D, Sunsaneevithayakul P: Relationship between 50 -g glucose challenge test and large for gestational age infants among pregnant women without gestational diabetes. J Obstet Gynaecol2019, 39(2):141-146.

9. Wei DM, Zhang B, Shi YH, Zhang L, Zhao SG, Du YZ, Xu LZ, Legro RS, Zhang HP, Chen ZJ: Effect of Preconception Impaired Glucose Tolerance on Pregnancy Outcomes in Women With Polycystic Ovary Syndrome. J Clin Endocr Metab 2017, 102(10):3822-3829.

10. Kouhkan A, Khamseh ME, Moini A, Pirjani R, Arabipoor A, Zolfaghari Z, Hosseini R, Baradaran HR: Diagnostic Accuracy of Body Mass Index and Fasting Glucose for The Prediction of Gestational Diabetes Mellitus after Assisted Reproductive Technology. International Journal of Fertility \& Sterility 2019, 13(1):32-37.

11. Chinese Diabetes S, National Offic for Primary Diabetes C: [National guidelines for the prevention and control of diabetes in primary care(2018)]. Zhonghua Nei Ke Za Zhi 2018, 57(12):885-893. 
12. Bao YQ: [Interpretation of blood glucose measurement in national guidelines for the prevention and control of diabetes in primary care(2018): early diagnosis and standard monitoring]. Zhonghua Nei Ke Za Zhi 2019, 58(4):318-320.

13. Use of glycated haemoglobin (HbA1c) in the diagnosis of diabetes mellitus. Diabetes Research and Clinical Practice 2011, 93(3):299-309.

14. Zimmet P, Alberti KGMM, Shaw J: Global and societal implications of the diabetes epidemic. Nature 2001, 414(6865):782-787.

15. Wei YM, Yang HX: [Characteristics of pre-gestational diabetes mellitus diagnosed during pregnancy and the effects on pregnancy outcomes]. Zhonghua fu chan ke za zhi 2017, 52(4):227-232.

16. Liu J, Zhang SK, Liu M, Wang QM, Shen HP, Zhang YP: Maternal pre-pregnancy infection with hepatitis B virus and the risk of preterm birth: a population-based cohort study. Lancet Global Health 2017, 5(6):E624-E632.

17. Zhou QJ, Wang QM, Shen HP, Zhang YP, Zhang SK, Li XT, Acharya G: Rubella virus immunization status in preconception period among Chinese women of reproductive age: A nation-wide, cross-sectional study. Vaccine 2017, 35(23):3076-3081.

18. Pan Y, Zhang SK, Wang QM, Shen HP, Zhang YP, Li YY, Yan DH, Sun LZ: Investigating the association between prepregnancy body mass index and adverse pregnancy outcomes: a large cohort study of 536098 Chinese pregnant women in rural China. Bmj Open 2016, 6(7).

19. Chamberlain JJ, Rhinehart AS, Shaefer CF, Jr., Neuman A: Diagnosis and Management of Diabetes: Synopsis of the 2016 American Diabetes Association Standards of Medical Care in Diabetes. Ann Intern Med 2016, 164(8):542-552.

20. American Diabetes A: 2. Classification and Diagnosis of Diabetes: Standards of Medical Care in Diabetes-2019. Diabetes Care 2019, 42(Suppl 1):S13-S28.

21. American Diabetes A: 15. Diabetes Care in the Hospital: Standards of Medical Care in Diabetes-2019. Diabetes Care 2019, 42(Suppl 1):S173-S181.

22. Mills KT, Bundy JD, Kelly TN, Reed JE, Kearney PM, Reynolds K, Chen J, He J: Global Disparities of Hypertension Prevalence and Control A Systematic Analysis of Population-Based Studies From 90 Countries. Circulation 2016, 134(6):441-+.

23. Wang T, Zhang J, Lu X, Xi W, Li Z: Maternal early pregnancy body mass index and risk of preterm birth. Arch Gynecol Obstet 2011, 284(4):813-819.

24. Jia W: Obesity in China: its characteristics, diagnostic criteria, and implications. Front Med 2015, 9(2):129-133.

25. Zhu L, Zhang R, Zhang S, Shi W, Yan W, Wang X, Lyu Q, Liu L, Zhou Q, Qiu Q et al: [Chinese neonatal birth weight curve for different gestational age]. Zhonghua Er Ke Za Zhi 2015, 53(2):97-103.

26. Catalano PM, Mclntyre HD, Cruickshank JK, McCance DR, Dyer AR, Metzger BE, Lowe LP, Trimble ER, Coustan DR, Hadden DR et al: The Hyperglycemia and Adverse Pregnancy Outcome Study Associations of GDM and obesity with pregnancy outcomes. Diabetes Care 2012, 35(4):780-786.

27. Filardi T, Tavaglione F, Di Stasio M, Fazio V, Lenzi A, Morano S: Impact of risk factors for gestational diabetes (GDM) on pregnancy outcomes in women with GDM. J Endocrinol Invest 2018, 41(6):671-676.

28. Peng HY, Li MQ, Li HP: MiR-137 restricts viability and migration of HTR-8/SVneo cells by downregulating FNDC5 in gestational diabetes mellitus. Curr Mol Med 2019.

29. Xing B, Wang L, Li Q, Cao Y, Dong X, Liang J, Wu X: Human embryonic stem cell-derived pancreatic endoderm alleviates diabetic pathology and improves reproductive outcome in C57BL/KsJ-Lep(db/+) gestational diabetes mellitus mice. Nutr Res 2015, 35(7):603-609. 
30. Starikov RS, Inman K, Has P, Iqbal SN, Coviello E, He M: Correlation of placental pathology and perinatal outcomes with Hemoglobin A1c in early pregnancy in gravidas with pregestational diabetes mellitus. Placenta 2017, 52:94-99.

31. Riskin-Mashiah S, Younes G, Damti A, Auslender R: First-Trimester Fasting Hyperglycemia and Adverse Pregnancy Outcomes. Diabetes Care 2009, 32(9):1639-1643.

32. Riskin-Mashiah S, Damti A, Younes G, Auslender R: First trimester fasting hyperglycemia as a predictor for the development of gestational diabetes mellitus. Eur J Obstet Gyn R B 2010, 152(2):163-167.

33. Kwik M, Seeho SK, Smith C, McElduff A, Morris JM: Outcomes of pregnancies affected by impaired glucose tolerance. Diabetes Res Clin Pract 2007, 77(2):263-268.

34. Chan JCN, Malik V, Jia W, Kadowaki T, Yajnik CS, Yoon K-H, Hu FB: Diabetes in Asia Epidemiology, Risk Factors, and Pathophysiology. Jama-J Am Med Assoc 2009, 301(20):2129-2140.

35. Kong LH, Nilsson IAK, Gissler M, Lavebratt C: Associations of Maternal Diabetes and Body Mass Index With Offspring Birth Weight and Prematurity. Jama Pediatr 2019, 173(4):371-378.

36. Ricart W, Lopez J, Mozas J, Pericot A, Sancho MA, Gonzalez N, Balsells M, Luna R, Cortazar A, Navarro P et al: Maternal glucose tolerance status influences the risk of macrosomia in male but not in female fetuses. $J$ Epidemiol Commun H2009, 63(1):64-68.

37. Tang JJ, Zhu X, Li M, Huang D, Zhao Q: The impact of maternal pre-pregnancy impaired fasting glucose on preterm birth and large for gestational age: a large population-based cohort study. Am J Obstet Gynecol 2019.

38. Salman L, Arbib N, Shmueli A, Krispin E, Wiznitzer A, Hadar E: The association between pre-pregnancy impaired fasting glucose and adverse perinatal outcome. Diabetes Research and Clinical Practice 2018, 140:148-153.

39. Landon MB, Thom E, Spong CY, Carpente M, Mele L, Johnson F, Tillinghast J, Anderson G: The national institute of child health and human development maternal-fetal medicine unit network randomized clinical trial in progress. Diabetes Care 2007, 30:S194-S199.

\section{Figures}




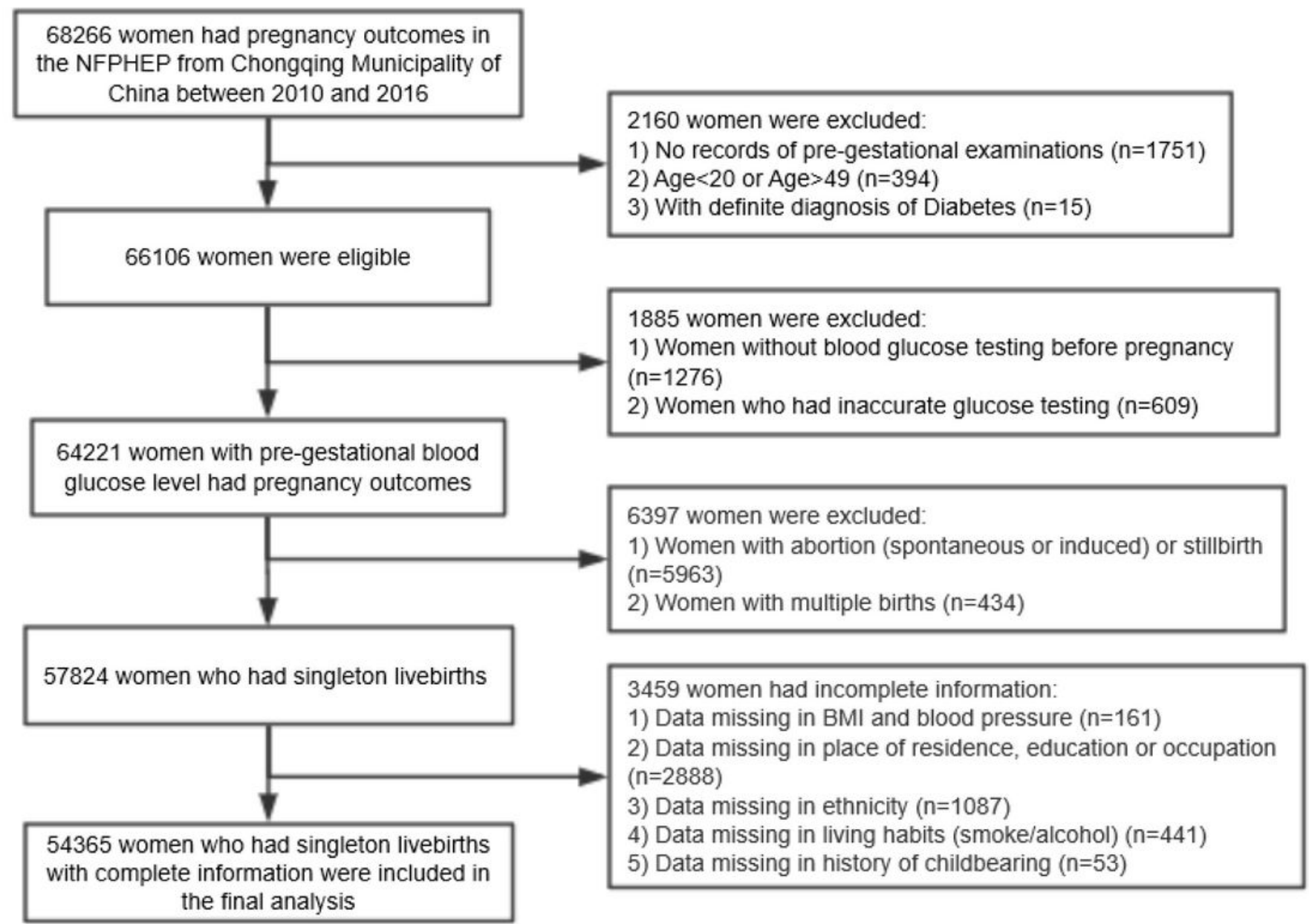

Figure 1

Flowchart for the study population 


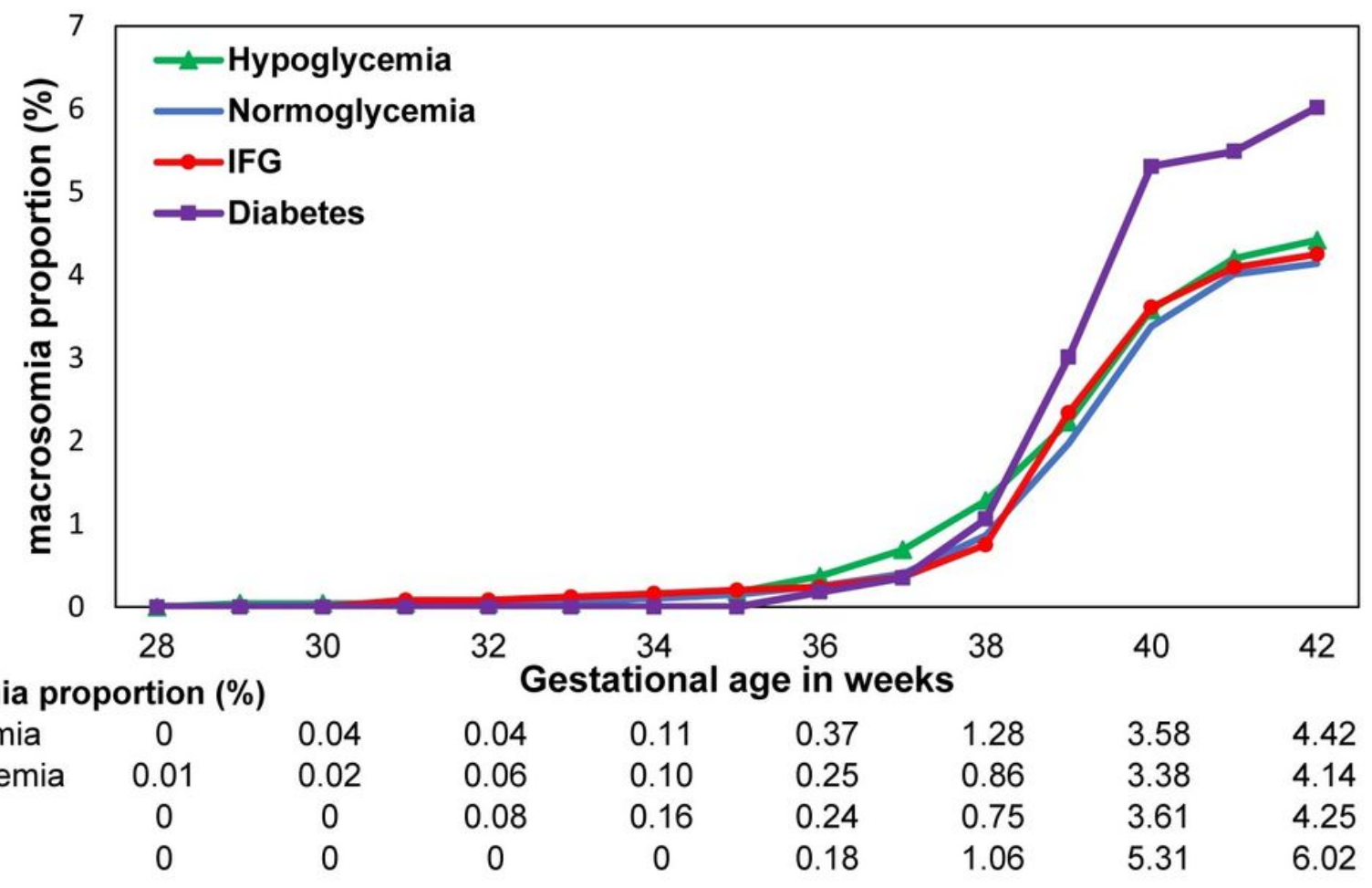

Figure 2

Cumulative occurrence of macrosomia according to pregestational glucose 


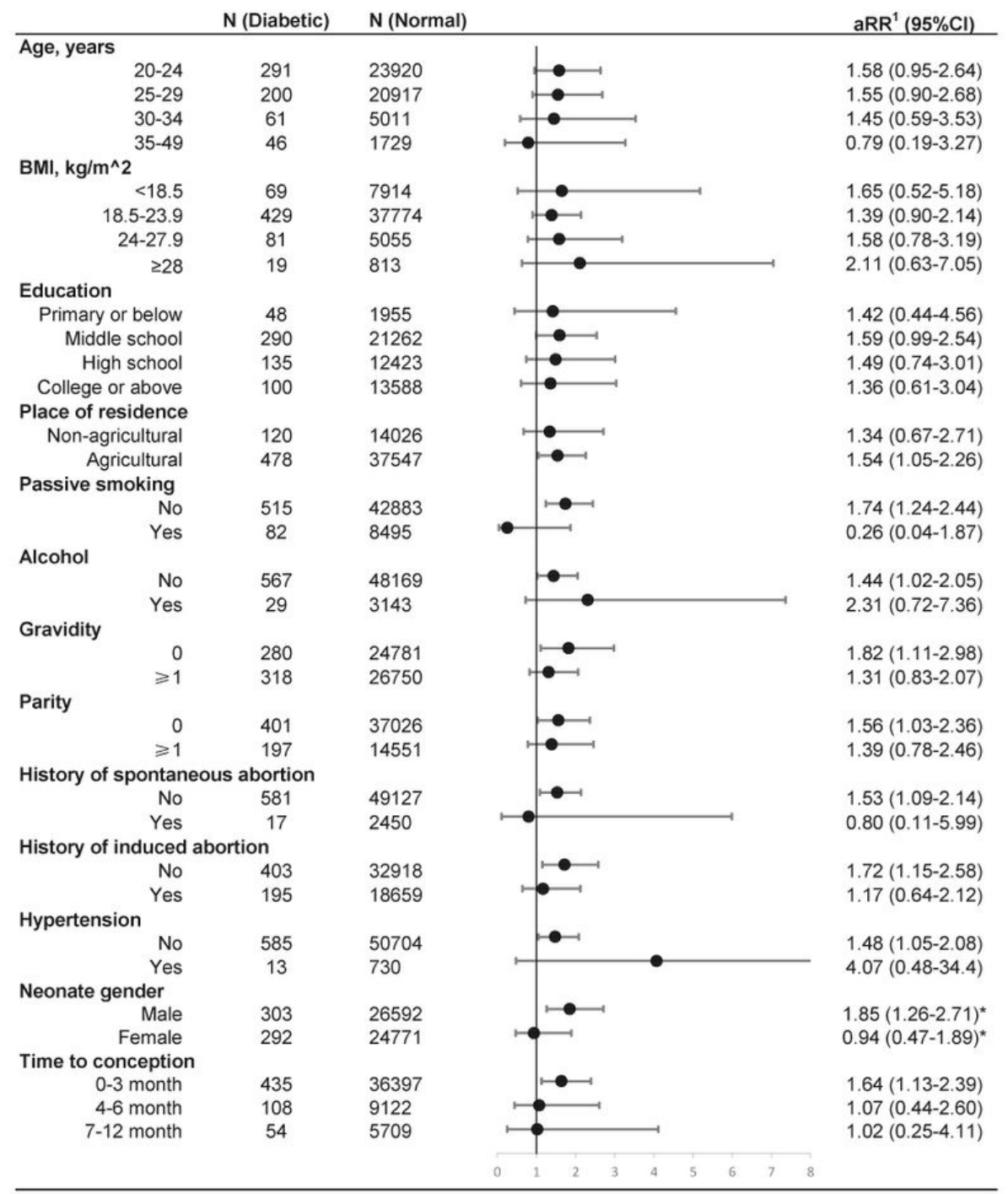

'After adjusting maternal age, BMI, ethnicity, education level, occupation, place of residence, smoking, passive smoking, alcohol, gravidity, history of preterm birth, history of abortion (spontaneous \& induced), hypertension and neonate gender.

*Additional adjustment for the gestational age in days.

\section{Figure 3}

Subgroup analysis of macrosomia in the pregestational diabetic compared to the pregestational normoglycemia

\section{Supplementary Files}

This is a list of supplementary files associated with this preprint. Click to download.

- supplementfigureS1.tif 